\title{
NEW METHODS FOR SPECIFICATION LATENT LOSSES FOR ELECTRICITY TRANSMISSION BY OVERHEAD LINES
}

\author{
Luboš PAVLOV, Luboš SKURČÁK \\ Department of Science, Research, Development and Analysis, \\ VUJE, a.s., Okružná 5, 91864 Trnava, Slovak Republic, tel. +421 33599 2321, \\ E-mail: lubos.pavlov@vuje.sk, lubos.skurcak@vuje.sk
}

\begin{abstract}
The submitted contribution is devoted to the issue of the existence of latent losses on the overhead lines. Quantification of latent losses of electricity is a very complicated task, which has been solved in practice for several years. In their assessment, however, often appear some inconsistencies which cause is often unknown. The magnitude of these losses in some cases cannot be negligible. From the point of view of maintaining an efficient and reliable operation of distribution and transmission systems in the future, attention will still need to be paid to the problem of latent loss analysis.
\end{abstract}

Keywords: latent losses, impedance asymmetry, overhead lines, synchronous phasor monitoring, AlFe conductors, magnetization losses

\section{INTRODUCTION}

The difficulty of solving the task of quantification of latent losses of electricity consists in possibilities of data gain from the real system operation and subsequent data postprocessing. Each latent losses of electricity researcher has asked himself the same questions: What is the cause of their occurrence? What is their size? How can we reduce the size of these losses or eliminate them?

Significant progress in measuring or computing technology brings new possibilities for a deeper and more detailed analysis of total electricity losses, its individual components, and to get answers to the above questions. Components of the total losses that have so far been included in the latent loss of electricity range are e.g. also losses due to impedance asymmetry and magnetizing losses in AlFe cables of the overhead lines.

\section{LOSSES DUE TO IMPADANCE ASYMETRY}

Non-transposed overhead lines are a typical asymmetrical element of the power system. The cause of the asymmetry is the longitudinal impedance inhomogeneity, caused by:

- configuration of the masts with position of phase conductors and ground ropes in specific sections of the overhead line,

- phase sequence on mast brackets for double lines,

- paralleling with other line, etc.

The magnitude of the impedance asymmetry of the overhead line can also be affected by its own asymmetrical operating modes. These are forced by the asymmetry of the phasors of nodal voltages star and the branch currents of the individual phases due to the asymmetric load $[2,3$, $11]$.

To simplify calculations, in practice, impedance unbalance from mutual interfacial inductive-capacitance linkages is often neglected and the 3-phase network is interpreted as symmetrical in the calculations. In this case, it is possible to determine only some components of losses such as ohmic losses, corona losses, leakage, and so on. The impact of impedance asymmetry can be quantified using three-phase conduction models based on theoretically derived interfacial inductance and capacitance values. More accurate results can, however, be obtained by computing using synchronic phasor monitoring results.

Determining the effect of the impedance asymmetry of the OHL on the efficiency of transmission or distribution of electricity can be achieved by using a vector record of electrical quantities at the input and output of the investigated line and the subsequent calculation of the operating impedance and admittance matrices. The calculation of the operating impedance and admittance matrices results from the 3-phase impedance $\left[\mathrm{Z}_{\mathrm{ABC}}\right]$ and admittance $\left[\mathrm{Y}_{\mathrm{ABC}}\right]$ matrix of the individual phases in general of the $3^{*} n$-conductor system with ground ropes in the matrix form, which content their own (again ground) and inter-phase inductive and capacitance bonds between all conductors. For the calculation of impedance and admittance matrices, the following input data are required: mast configuration, voltage level, conductor length, phase and ground conductor type, geometric distribution of phase wires at masts, type and number of masts, amount of power transmitted by line $[4,5,6,12]$.

The results of the project in the past confirmed the usability of the synchronous phasor monitoring to determine the size of the loss by asymmetry of the overhead lines. Vector records of operating variables $u(t)$ and $\mathrm{i}(\mathrm{t})$ were recorded by PMU DEWE 571 (synchronous phasor measuring assemblies with a sampling frequency of $100 \mathrm{kHz}$ ). As an example, we report monitoring results on a simple $220 \mathrm{kV}$ electric line with a length of $78,754 \mathrm{~km}$, consisting predominantly of Portal type masts. On the line is installed a phase conductor of the type $1 \times 3 \times 3 \times 450 \mathrm{AlFe} 6$ and as earth ropes are used AlFe 38/32, $\mathrm{AlFe} 42 / 25$ and $70 \mathrm{Fe}$.

Measurements were made in October between 9:00 am and 2:00 pm in dry sunny weather at an average air temperature of $17^{\circ} \mathrm{C}$. 
Based on the processing of the measurement results, the average loss due to impedance imbalance value was
$26 \mathrm{~kW}$ (Fig. 1). This figure represented an average of $5.7 \%$ of the total losses of the external line.

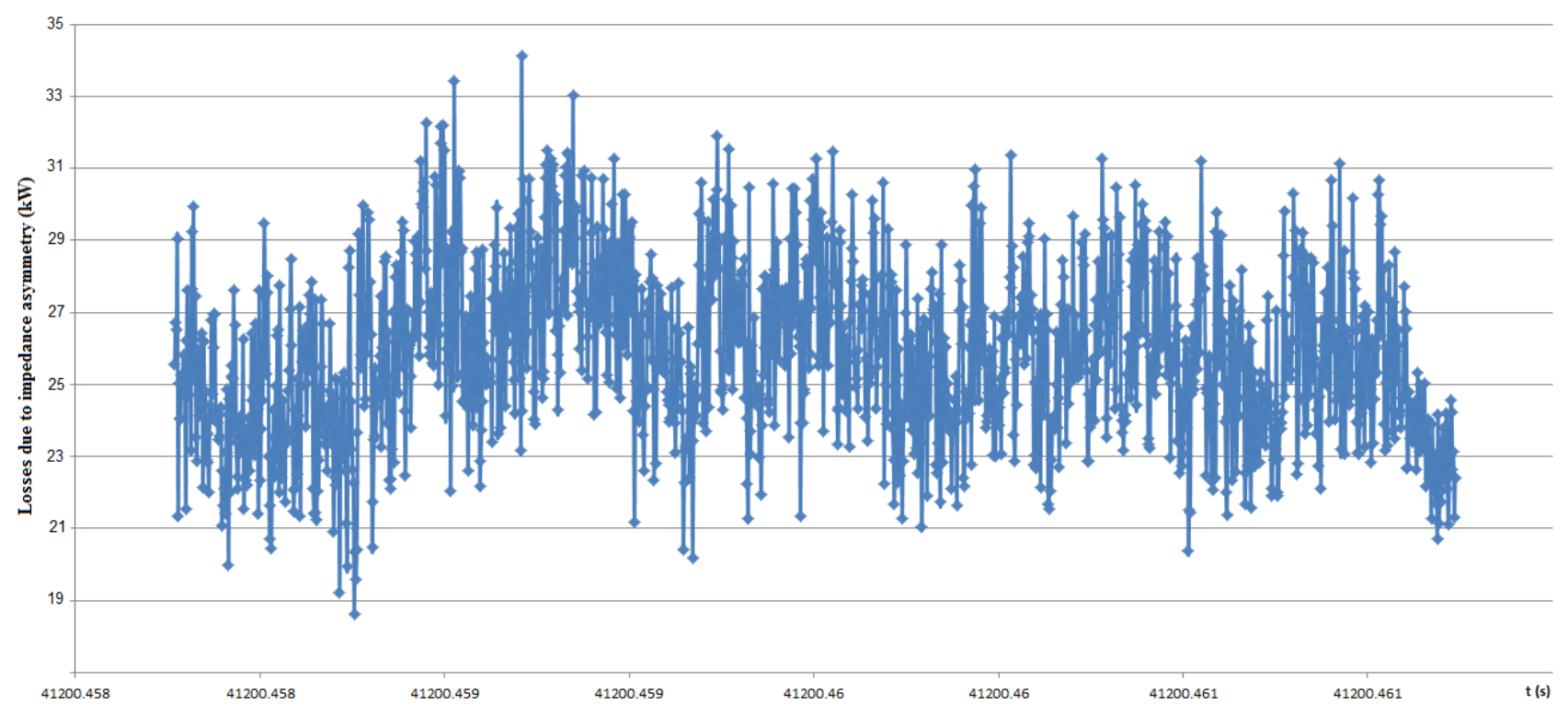

Fig. 1 Losses due to impedance asymmetry

\section{MAGNETIZATION LOSSES IN ALFE CONDUCTORS}

Magnetization losses in steel-aluminium rope conductors AlFe type are an undesirable phenomenon resulting in an increase and non-linearity of the ratio of their AC resistance to $\mathrm{DC} \mathrm{k}_{\mathrm{R}}=\mathrm{R}_{\mathrm{AlFe}} / \mathrm{R}_{\mathrm{AlFe}}=$ over the entire current load range. Due to the magnetizion of the $\mathrm{AlFe}$ steel core by current flowing through spirally rolled layers of aluminium wires, an increase in $\mathrm{AC}$ resistance of AlFe rope $\Delta \mathrm{R}_{\mathrm{AlFe}} \Omega . \mathrm{km}^{-1}$ and the gain of active losses $\Delta \mathrm{R}_{\mathrm{AlFe}} . \mathrm{I}^{2}$ $\mathrm{W}$ is generated.

On HV and EHV overhead lines, thousands of kilometres of Al-Aluminium, AlMgSi-Aluminium Alloy or combined AlFe-Aluminium-steel conductors have been installed so far. The drawback of using AlFe-aluminiumsteel conductors on the OHL is their steel core, which is magnetized by counter-spirally rolled Al-wire layers. Its relative complex permeability $\mu_{\mathrm{rFe}}$ non-linearly change till the state of saturation, as well as the AC resistance of the rope $\mathrm{R}_{\mathrm{AlFe}} \sim \Omega \mathrm{km}^{-1}$ and $\mathrm{AC} / \mathrm{DC}$ resistance ratio of $\mathrm{AlFe}$ rope $k_{R}=R_{A l F e} / R_{A l F e}$, depending on the size of the total current flowing the $\mathrm{AlFe}$ rope $\mathrm{I}_{\mathrm{AlFe}} \mathrm{A}$ (more precisely from its redistribution to the individual oppositely winded layers of aluminium wires). From the magnetic induction in the AlFe steel core depend the total magnetizing losses $\left(\mathrm{P}_{\mathrm{H}}+\mathrm{P}_{\mathrm{V}}\right) \mathrm{W} \cdot \mathrm{km}^{-1}$, the increase of AlFe rope AC resistance $\Delta \mathrm{R}_{\mathrm{AlFe}} \sim \Omega \mathrm{km}^{-1}$ and so the Joule losses $\mathrm{P}_{\mathrm{J}} \mathrm{W} \cdot \mathrm{km}^{-1}$. It also influences the amount of allowed current load $\mathrm{I}_{\mathrm{AlFe}}$ dov $\mathrm{A}$ and hence the transmission capability of the overhead line.

These disadvantages of conventional rope conductors have been eliminated by the use of new Aluminum Conductor with Composite Core (ACCC), which are a good technical solution to the AlFe $=$ ACSR (Aluminum Conductor Steel Reinforced) problem when it is necessary to adhere permitted phase conductor flash-over distance on OHL from the ground.

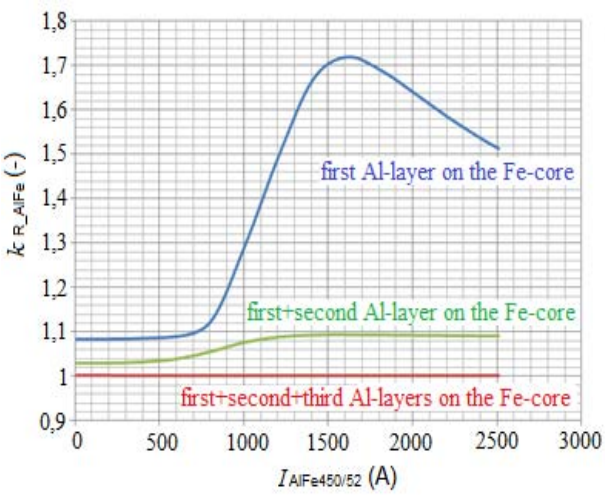

Fig. 2 Progress ratio of $A C$ to $D C$ resistance $k_{R}=R_{a c} A l F e$ $450 / 52 / R_{\text {dc_AlFe } 450 / 52}$ (-) gradually adding layers of Al-wires on steel core, 3-layer rope wire $\mathrm{AlFe} 450 / 52$

Specific calculations of the electrical parameters $\left(k_{R}\right.$, $\left.\mathrm{R}_{\mathrm{AlFe}} \sim, \mathrm{I}_{\mathrm{AlFe} \_ \text {dov }}\right)$ from known magnetic characteristics of the steel core wire of $\mathrm{d}_{\mathrm{Fe}}=2,36 \mathrm{~mm}$ according to the input Table1, were made for the cross-section of the cable conductor AlFe 450/52 composed of $(3+9) / 2,36 \mathrm{~mm} \mathrm{Fe}-$ wires $+(12+18+24) / 3,25 \mathrm{~mm} \mathrm{Al-wires,} \mathrm{i.e.} \mathrm{for} \mathrm{rope}$ conductor with three layers of aluminium wires. The nonlinearity of the AC resistivity coefficient due to the magnetization of the steel core $k_{R}=R_{A l F e} \sim / R_{A l F e}=$ due to magnitude of the current load can generally be totally excluded in the AlFe rope with $\mathrm{n}$ even number of aluminium wires layers oppositely spirally winded around the steel core of the AlFe rope as their magnetizing effect in steel core is always almost completely compensated.

On the other hand, the AlFe ropes with an odd number of aluminium wires layers is never completely compensated, and although the magnetizing effect of one Al-Wire layer always prevails, it can be eliminated by increasing the slope of the first layer of Al-wires (Fig. 3). 


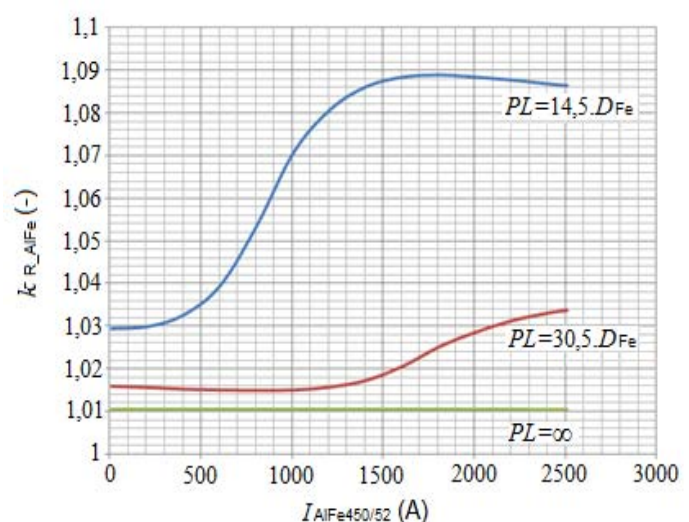

Fig. 3 Progress ratio of AC to DC resistance $k_{\mathrm{R}}=R_{\mathrm{ac}} \mathrm{AlFe}$ $450 / 52 / R_{\text {dc_AlFe }} 450 / 52$ (-) when changing the pitch of the first Allayer 3-layer wire rope wire ACSR 450/52
Ideally this would be the case for AlFe ropes with an odd number of aluminium wires layers if their first layer of Al-wires would be replaced by a direct aluminium tube without circulating the current around the steel core $[9,10]$.

From Table 1 resulting that, for example, with the average magnetic induction $\mathrm{B}=0,15 \mathrm{~T}$ in each steel wire of 2,36 $\mathrm{mm}$ and $1 \mathrm{~km}$ length of rope conductor AlFe 450/52 would be:

- hysteresis losses in one steel wire $\mathrm{P}_{\mathrm{H}}=66,70 \mathrm{~W} \cdot \mathrm{km}^{-1}$,

- loss by eddy currents $\mathrm{P}_{\mathrm{V}}=6,00 \mathrm{~W} \cdot \mathrm{km}^{-1}$ and

- total watt losses due to AC magnetization for $50 \mathrm{~Hz}$ frequency $\mathrm{P}=72,70 \mathrm{~W} \cdot \mathrm{km}-1$.

Table 1 Magnetic characteristics of ACSR 450/52 wire, 2,36 (mm) diameter, at $25\left[{ }^{\circ} \mathrm{C}\right]$

\begin{tabular}{|r|r|c|c|c|c|c|c|c|c|}
\hline $\begin{array}{r}\mathrm{H} \\
{\left[\mathrm{A} \cdot \mathrm{m}^{-1}\right]}\end{array}$ & $\begin{array}{r}\mathrm{B} \\
{[\mathrm{T}]}\end{array}$ & $\begin{array}{r}\mathrm{P}_{\mathrm{H}} \\
{\left[\mathrm{W} \cdot \mathrm{km}^{-1}\right]}\end{array}$ & $\begin{array}{r}\mathrm{P}_{\mathrm{V}} \\
{\left[\mathrm{W} \cdot \mathrm{km}^{-1}\right]}\end{array}$ & $\begin{array}{r}\mathrm{P} \\
{\left[\mathrm{W} \cdot \mathrm{km}^{-1}\right]}\end{array}$ & $\begin{array}{r}\operatorname{tg} \delta \\
{[-]}\end{array}$ & $\begin{array}{r}\delta \\
{\left[{ }^{\circ}\right]}\end{array}$ & $\begin{array}{r}\boldsymbol{\mu}_{\mathrm{r}} \\
{[-]}\end{array}$ & $\begin{array}{r}\operatorname{Re}\left(\boldsymbol{\mu}_{\mathrm{r}}\right) \\
{[-]}\end{array}$ & $\begin{array}{r}\operatorname{Im}\left(\boldsymbol{\mu}_{\mathrm{r}}\right) \\
{[-]}\end{array}$ \\
\hline 0,000 & 0,000 & 0,0 & 0,0 & 0,0 & 0,00 & 0,00 & 0,0 & 0,0 & 51,47 \\
\hline 764,2 & 0,155 & 66,7 & 6,0 & 72,7 & 0,76 & 37,25 & 161,3 & 97,6 & 128,4 \\
\hline 951,0 & 0,310 & 154,5 & 15,9 & 170,4 & 0,826 & 39,57 & 259,2 & 165,1 & 199,8 \\
\hline 1086,8 & 0,465 & 280,9 & 37,7 & 318,6 & 1,005 & 45,14 & 340,2 & 241,1 & 240,0 \\
\hline 1213,5 & 0,620 & 435,4 & 67,4 & 502,8 & 1,106 & 47,87 & 406,2 & 301,3 & 272,5 \\
\hline 1341,6 & 0,775 & 600,4 & 109,1 & 709,5 & 1,159 & 49,21 & 459,3 & 347,7 & 300,1 \\
\hline 1483,0 & 0,930 & 758,4 & 170,6 & 929,0 & 1,146 & 48,89 & 498,6 & 375,7 & 327,8 \\
\hline
\end{tabular}

\section{CONCLUSIONS}

These results point to possible ways of quantifying some components of latent losses. Knowing the causes of their occurrence and quantifying their size is important in determining a procedure to reduce losses. Applying appropriate techniques to reduce them will make it easier to increase effectivity of transfer and distribute of electricity, which is currently a cross-cultural theme and one of the priorities of European energy policy.

The size of the impedance asymmetric losses on overhead line depends on the design parameters (geometrical arrangement and layout of the wires), but also on the ES (load) mode of operation. Applying the monitoring of synchronous phasors on the overhead line and using measured data to calculate impedance and admittance matrices, it is possible to determine the magnitude of impedance asymmetry. One way to reduce the loss due to asymmetry on the overhead lines is to replace the position of the wires on the line by twisting. Twists can be complete (all wires change their position) or partial (only two wires change their position). For example, by symmetrizing the $220 \mathrm{kV}$ overhead lines at three locations, each one-third of the length of the line, it is possible to reduce asymmetric losses by $40-60 \%$.

In the case of two-layer AlFe ropes, the $\mathrm{AC}$ resistance $\mathrm{R}_{\mathrm{AlFe}} \Omega \cdot \mathrm{km}^{-1}$ is independent of the current load. This independence is common to AlFe ropes with even number of Al-layers. For AlFe ropes with an odd number of Allayers, the AC resistance is not dependent on the current load if the first Al layer is replaced by an aluminium tube. It is a way of reducing both Joule's losses in AlFe rope conductor and magnetization losses in his steel core.

\section{ACKNOWLEDGMENTS}

This work was supported by the Slovak Research and Development Agency under the contract No. APVV-150464.

\section{REFERENCES}

[1] WU, A. - NI, B.: Line Loss Analysis and Calculation of Electric Power Systems, October 2015, ISBN: 9781118867235.

[2] PHADKE, A. G. - THORP, J. S.: Synchronized Phasor Measurements and Their Applications. Springer. USA.

[3] SHI, D.: Utilizing synchrophasor technology to determine transmission line impedance parameters. Arizona State University. USA. 
[4] DAS, J. C.: Understanding Symetrical Components for Power System Modeling, February 2016, WileyIEEE Press, ISBN: 9781119226857.

[5] SINGH, B. - SHARMA, K. N. - TIWARI, N. A. VERMA, S. K. - SINGH, N. S.: Applications of phasor measurement units (PMUs) in electric power system networks incorporated with FACTS controllers, International Journal of Engineering, Science and Technology Vol. 3, No. 3, 2011.

[6] IEEE Standard for Synchrophasors for Power Systems. IEEE Std C37.118 ${ }^{\mathrm{TM}}-2005$. USA.

[7] CIGRÉ BROCHURE 207, “ Thermal Behaviour of Overhead Condutors", Study Committee 22 Working Group 12, August 2002.

[8] WAREING, B.: "Types and Uses of High Temperature Conductors", Working Group SC B2, Technical Advisory Group B2-AG-06, Cigré AG06 Seminar Bangkok.

[9] MATSCH, L. W. - LEWIS, W. A.: "The Magnetic Properties of ACSR Core Wires", Power Apparatus and Systems, Part III., Transactions of the American Institute of Electrical Engineers, vol. 77, Issue 3., pp. 1178-1189, April 1958.

[10] LAGO, J. - KOVAČIČ, J.: “Zníženie strát v AlFe lanách“, Výskumná správa VVZ vedení vvn, Elektrovod k.p, Čulenova, 89122 Bratislava, Bratislava, December 1982.

[11] PAVLOV, L'. - SKURČ́AK, L'.: Latent Losses on the Overhead Line. CPC 2018, Tantranské Matliare, 2018.
[12] PAVLOV, L. - SKURČÁK, L. - CHOVANEC, J. ALTUS, J.: Impact of impedance unbalance on the efficiency of electricity transmission and distribution - A case study, Journal of electrical engineering, Vol. 68, No. 6, (2017), 492-495.

Received September 13, 2018, accepted November 15, 2018

\section{BIOGRAPHIES}

Luboš Pavlov (Ing, PhD), born in 1986, graduated in power engineering from the Faculty of Electrical Engineering of the Zilina University in Zilina in 2010. In 2016, he obtained the $\mathrm{PhD}$ degree in electrical power engineering from the Faculty of Electrical Engineering of the Slovak University of Technology in Bratislava in Bratislava. Since 2010 he has worked at VUJE, a.s. in the Division for the support of the management and operation of the power system.

Luboš Skurčák (Ing, $\mathrm{PhD}$ ), born in 1974, graduated from the Faculty of Electrical Engineering and Information Technology of the Slovak University of Technology in Bratislava in 1999. In 2015, he obtained the PhD degree in electrical power engineering from the same faculty. Since 1999 he has worked at VUJE, a.s. in the Division for the support of the management and operation of the power system. He is a member of the National Committee of the Czech Republic and Slovak Republic CIGRE. 